\title{
Use of scenario development and personal learning environment and networks (PLE\&N) to support curriculum co- creation
}

\author{
Eric TSUI \\ The Hong Kong Polytechnic University, Hong Kong, SAR Hong Kong \\ eric.tsui@polyu.edu.hk \\ Nikolina DRAGICEVIC \\ The Hong Kong Polytechnic University, Hong Kong, SAR Hong Kong \\ nikolina.dragicevic@connect.polyu.hk
}

\begin{abstract}
In much of the current discussions on business environments, a recurring theme both for academics and practitioners is that it is marked by inherent uncertainty (unknown unknowns). Hence, knowledge workers must have skills and understanding of the possible ways to navigate through and adapt to constant change. However, the tendency of prevailing approaches to curriculum development to focus on (static) learning outcomes, we argue, is not appropriate to train young people to adapt to the unpredictable working environment. Instead, more dynamic approaches to curriculum are required, which would instead focus on learning as a continuous relearning and emergent process of adaptation and stimulate students inquiry and intellectual and creative skills. This paper approaches the issue by discussing the opportunities of using scenario thinking and development together with a personal learning environment and network (PLE\&N) for co-creating a curriculum with students, teachers, and practitioners in higher education. In short, the methodology underpinning scenario development recognizes that uncertainty can be best dealt with and understood from the perspective of a range of possibilities and multiple futures through a facilitated, coherently structured process. PLE\&N, on the other hand, serves as a learning space which stimulates self-regulated and networkbased learning. The paper contends that curriculum informed by such a design methodology would lead to more frequent and appropriate updates as well as equip students with skills to work in a volatile, uncertain, complex, and ambiguous (VUCA) environment.
\end{abstract}

Keywords: co-creation of curriculum, curriculum renewal, scenario development, personal learning environment and network, student-centric.

Please cite the article as follows: Tsui, E. and Dragicevic, N. (2018), "Using the scenario development and personal learning environment and network to support curriculum design", Management \& Marketing. Challenges for the Knowledge Society, Vol., 13, No 2, pp. 848-858, DOI: 10.2478/mmcks2018-0009.

\section{Introduction}

Disruptive changes caused by massive new technological, social, political, economic, and educational driving forces are increasing the uncertainty and ambiguity in the business environment and reinventing the industries. These forces include technological advances such as cyber-physical systems, advanced types of machine learning and artificial intelligence; social factors such as changes in user values, platform business model, sharing economy; massive open online courses in education, relative declines in government support and others. Together with the exponential growth of digital transformation and 
vastness of digital data that has more entry points than ever before, these driving forces pose significant challenges for students who are entering the workforce in near future. Society is increasingly calling for knowledge workers with skills and understanding of the methods for dealing with these changes and working in the volatile, uncertain, complex, and ambiguous (VUCA) environment. Hence, preparing students to be not only knowledgeable in their disciplines, but also to be able to work in fast changing digital environments should be one thing higher education does especially well. Knowledge workers need to be equipped with skills to constantly sense the environment for change, reflect on the data, generate informed opinions of the trends and drivers in the environment, and to adapt.

Despite the growing demand for the above mentioned skills, higher education is still dominated by the classical view of learning depicted as a knowledge transfer from a teacher (or a textbook) to a rather passive student (Gherardi, Nicolini, \& Odella, 1998), which suggests that something is flawed with how higher education prepares their students to be knowledge workers in the contemporary society. Such a reductive account of how students should learn does not reflect the fact that in practice learners construct their knowledge through interaction with others and that what differs an expert from a novice is know-how, built based on the ability to reflect and act (Schön, 1984). Instead of on learning outcomes, the focus should be put on learning as a continuous relearning and emergent process of adaptation (Kolb, 1984). While discipline-based programs at universities provide the foundation training for a profession, the traditional classroom teaching environment does not offer sufficient opportunities for student active involvement in the construction of knowledge relevant for this profession. This is further reflected by the fact that curriculum design is predominantly regulated by national, institutional or teacher standards that specify what students should know. As well, the curriculum is not being renewed frequently.

We attribute at least part of the problems of today's higher education to the fact that it often fails to give the participatory role to students in construing the knowledge relevant to the subject field and that it lacks in mechanisms to continually renew the curriculum by involving students in curriculum design. In this paper, we address this issue by discussing the opportunities of using scenario development together with a personal learning environment and network (PLE\&N) for involving students in the co-creation of curriculum in higher education, particularly in rapidly evolving business and technological areas. The paper is structured as follows: First, we posit a research problem and provide a literature review of the basic concepts used in the paper. Then, we discuss the proposed approach and outline the multilayer, three-step model for a curriculum design.

\section{Literature review}

Some researchers already echoed the issue of curriculum renewal in their contention that there is a necessity of moving away from a fixed and static curriculum towards more dynamic conceptualizations of curriculum, with shortened life cycle (Albert \& Beatty, 2014; Chapman \& Randall, 2012; O'Keefe, 2013; Oliver, 2013). Though several methods to facilitate curriculum renewal exist (e.g., Oliver, 2013; Sitlington \& Coetzer, 2015), the literature on the subject area lacks unambiguous conceptual and practical guidance how to put processes in place to continuously maintain curriculum relevancy for teachers interested in such practice. Further on, albeit students' inputs have been taken into consideration particularly within the concept of the "open curriculum," a facilitated, Vol. 13, No. 2, Spring, pp. 848-858, ISSN 1842-0206 | Management \& Marketing. Challenges for the Knowledge Society 
coherently structured process for students' construction of relevant knowledge for curriculum design does not exist yet. The first and most compelling reason for this paper, hence, stems from the desire to increase the relevance of curriculum for educational practice by engaging students in its design. Particularly, the aim of this paper is to discuss an approach to curriculum design by opening the curriculum to students' inputs with particular emphasis on students' contributions to project the trends and developments of a field of study. A possible mean to achieve this objective is to increase students` engagement and to facilitate their knowledge co-creation with the support of scenario development techniques facilitated in the personal learning and network environment (PLE\&N) (Tsang \& Tsui, 2017). Scenario development is a very well-known method for coping with future changes, which makes it a suitable option for facilitating the participative and contributory student process of assessing the current trends and projecting the future developments of a subject field. PLE\&N is a virtual learning tool, aiming to enhance students` co-learning and co-creation of curriculum with peers, teachers, graduates, and practitioners. A literature search of curriculum design in higher education by the authors failed to reveal any use of these concepts in this particular way. In the following paragraphs, we introduce these concepts and highlight potential benefits of their use.

\section{Scenario development}

Scenarios have been defined in various ways. For example, Ogilvy \& Schwartz (2004, p. 2) define scenarios as "hypotheses of different futures specifically designed to highlight the risks and opportunities involved in specific strategic issues." Other researchers have similar definitions. For instance, Ringland \& Schwartz (1998, p. 2) defined scenarios as "That part of strategic planning which relates to the tools and technologies for managing the uncertainties of the future." Van Notten (2006, p. 71) gives one more recent, comprehensive account of scenarios: "Scenarios are consistent and coherent descriptions of alternative hypothetical futures that reflect different perspectives on past, present, and future developments, which can serve as a basis for action."

A distinctive feature of scenarios, it is argued, is that they are not predictions or forecasts asserting that something will happen; instead, they are multiple, plausible futures asserting changes that might happen (Chermack, Lynham \& Ruona, 2001). That is, scenario development does not give one single answer about the future. On the contrary, it involves investigation of fundamental, macro industry uncertainties about the future and creation of compelling different stories how the future might unfold depending on how these uncertainties will evolve. In this way, scenario development helps to make sense of the future by facilitating interpretation of the overload of data and information (Duncan and Wack, 1994). For these reasons, scenario development has been particularly recognized to be helpful in situations of great uncertainty and discontinuity (Schoemaker, 2015). By fleshing out several scenarios for future development, participants involved in the scenario development activities are stretching out space, within which future development will occur. Fundamentally, scenario thinking means viewing the world as a story with various more or less controllable forces and a number of actors trying to influence the plot. Scenarios are "stories about the way the world might turn out tomorrow, stories that can help us recognize and adapt to changing aspects of our present environment" (Schwartz, 1991, p. 3). 
The practice of scenario development has no single method and dozens of techniques. However, some common characteristics for developing scenarios are listing key trends and driving forces, exploring relationships among them, determining uncertainties, creating the narratives. Scenario thinking starts from the outside-in view: it begins with scanning the environment and identifying early signals of changes that might, over time, profoundly affect the focal area of interest (as represented in Figure 1) (Lindgren \& Bandhold, 2004). Through the scenario development process, opportunities and threats of the emerging events can be identified and prioritized; they are signs which are sometimes referred to as "weak signals," "early warnings", "seeds" or "traces" (Masini \& Vasquez, 2000). Both qualitative tools, such as stories and pictures, and quantitative and computational tools can be used to depict scenarios (Amer, Daim, \& Jetter, 2013).

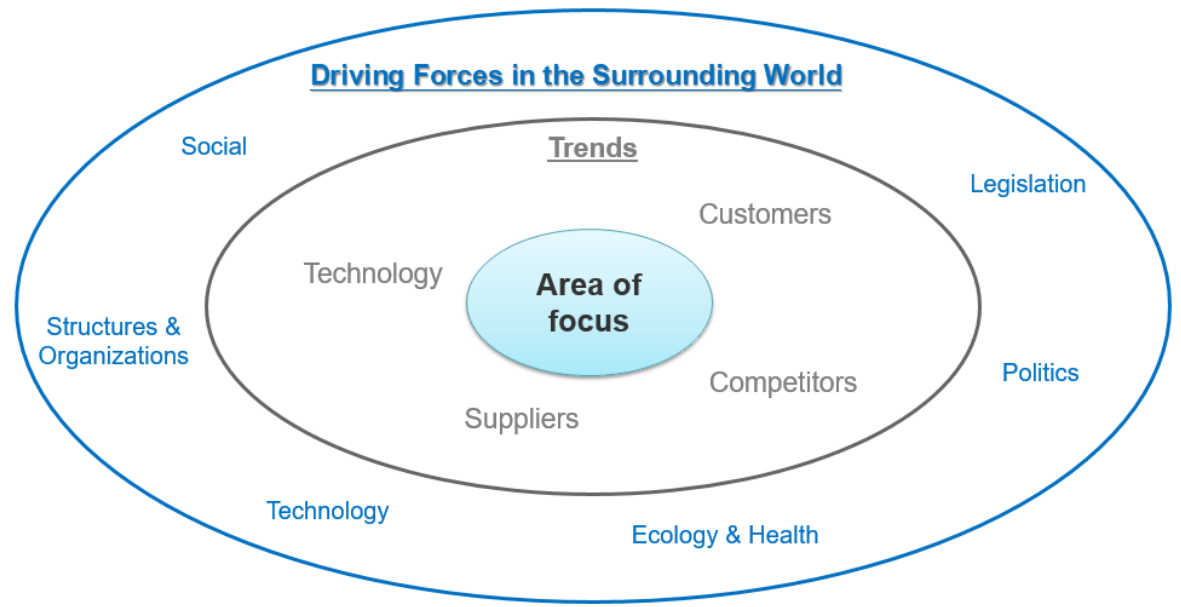

Figure 1. Outside-in view of scenario development

Source: Adapted from Lindgren \& Bandhold, 2004.

Scenario development has been used successfully to improve the quality of decision making, facilitate community dialogue, creating policy and organizational alignment, environmental scanning, planning tool (van der Merwe, 2008), standalone or in a combination with other methods such as technology road mapping (Cheng, Wong, Cheung, \& Leung, 2016). It is a practitioner-driven approach, meaning that it addresses the problem in close collaboration with practitioners and it values imaginative individuals or "remarkable people" whose role in scenario processes is to stretch the eyes of other participants to new ideas (Van der Heijden, 1996).

Scenario development activities, much as they are content related they are process related (Van Notten, 2006). Hence, applied to education, scenario development involves learning, exploration of the interaction among societal drivers, and imaginative thinking about the plausible future which may improve students' intellectual and creative skills (Schwartz, 1991; Van der Heijden, 2011; Van Notten, 2006). Further, scenario development seems to be suitable for facilitating construction of relevant knowledge base for the subject field since it is a social-reasoning process which facilitates dialogue among participants, allows identifying key drivers, stakeholders, trends in the subject field and relations among them, and bringing about alignment of thinking through development of narratives (van der Heijden et al. 2002).

Vol. 13, No. 2, Spring, pp. 848-858, ISSN 1842-0206 | Management \& Marketing. Challenges for the Knowledge Society 


\section{Personal learning environment \& network (PLE\&N)}

PLE\&N is a peer-based learner-centric platform which aims to foster self-regulated, network-based, and lifelong learning (Dabbagh \& Kitsantas, 2012; Leone, 2013; Tsui, Wang, \& Sabetzadeh, 2014; Tsang \& Tsui, 2017). The related literature identifies different variants of PLE\&N systems, such as personal knowledge environment (Leone, 2012) and personal knowledge networks (Mohamed, 2012).

Applied to education, PLE\&N facilitates interaction and collaboration among peer students, which is considered important for effective learning even after the formal classroom teaching session (García-Peñalvo et al., 2011). An important aspect of PLE\&N is the participation of practitioners and recent graduates in student learning activities (Tsang \& Tsui, 2017). Practitioners, teachers, and graduates have a role of "more knowledgeable others" (Vygotsky, 1980) in assisting students' learning and maintaining the industry relevance. Students' learning is influenced by social interactions with more knowledgeable others and their engagement significantly impacts their ways of thinking and interpretation of learning situations. Through these interactions, meaningful social context is created which helps students to construct an understanding of the subject concepts.

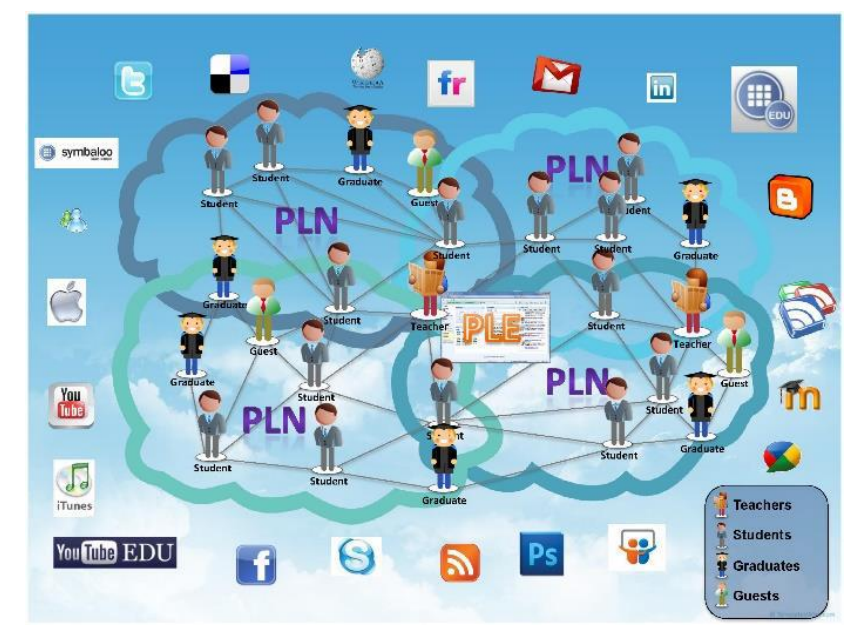

Figure 2. Example of a personal learning environment \& network

Source: Tsui, Wang, \& Sabetzadeh, 2014.

One of the key aspects of using PLE\&N is the use of technologies, particularly Web 2.0 tools, which allow learners to develop their personalized learning environments. Some of the benefits of the virtual environment are its ability to network students and others, stimulate reflection, and create the conditions for them to work at a distance to develop communities of practice. There are various possible applications to support PLE\&N, for example, social networking applications such as Facebook or Google+. Through PLE\&N, students get the chance to learn in the digitalized environment and to learn how to learn in a digitalized environment, which might be considered as a new form of a digital literacy.

Previous studies on PLE\&N using Google public tools in 8 subjects (Tsui, Tsui, \& SeeTo, 2013) and 12 subjects (Tsang \& Tsui, 2017) for over 3 semesters taught by teachers in the university in Hong Kong report about its effectiveness for social and lifelong learning. These findings support the decision to combine PLE\&N together with scenario development to facilitate co-creation of the curriculum.

Vol. 13, No. 2, Spring, pp. 848-858, ISSN 1842-0206 | Management \& Marketing. Challenges for the Knowledge Society 


\section{A model for curriculum co-creation}

We suggest a multi-step approach to curriculum co-creation by using scenario thinking and development together with a personal learning environment and network (PLE\&N). The general approach can be represented with a three-step model, which is in incremental and iterative cycles performed throughout the academic year (represented in Figure 3). The model depicts curriculum design with the central activity of students' scenario development in a technology-enabled learning environment. Since the students, i.e. main "users" of the curriculum have a central role, the model is user-centric. Given the active role of students but as well teachers, practitioners, and graduates who support students` work, the model is as well participatory driven. In the following paragraphs, we describe the components and steps implied by the model.

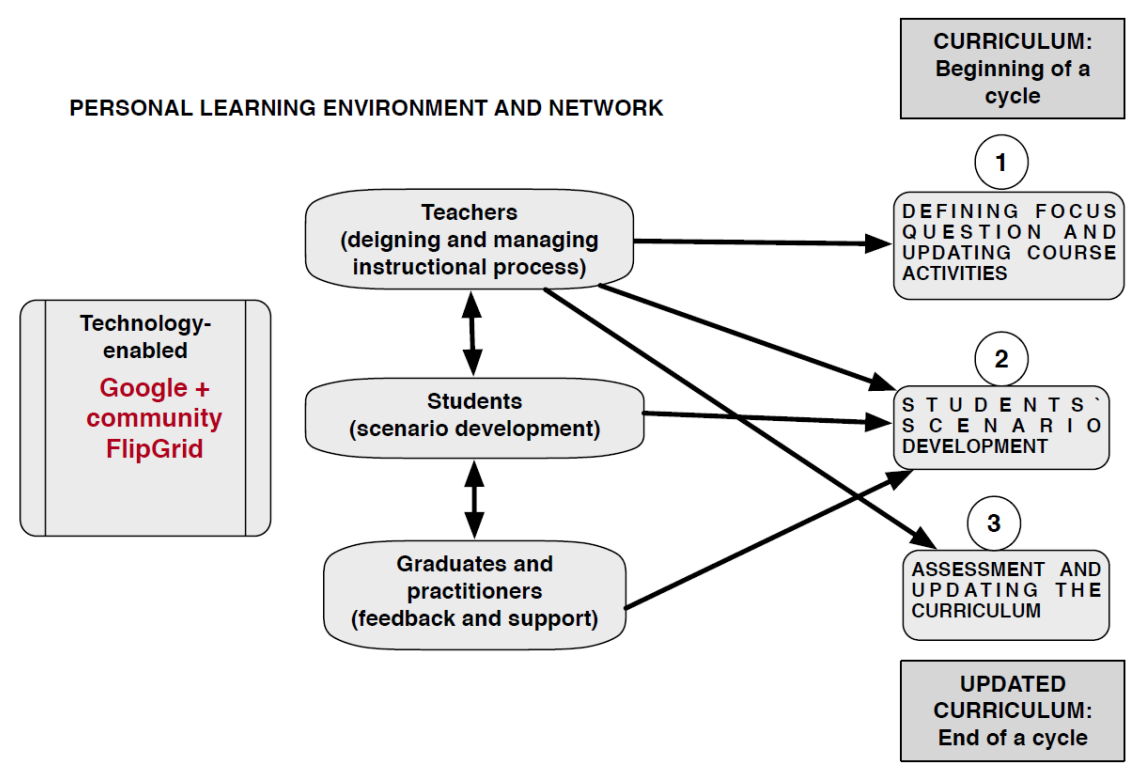

Figure 3. A model for curriculum co-creation and renewal

Source: Authors' own research.

\section{Components of the model}

Group composition for scenario development

The model consists of three participatory layers, namely, teachers' layer, students' layer, graduates,' and practitioners' layer (c.f., Tsang \& Tsui, 2017). Due to student centricity, the students' layer is depicted in the middle. The teacher's primary role shifts from dispensing information to designing and managing the overall instructional process, and the students' role shifts from being a passive recipient of information to one of accepting responsibility for the preparation of the course content and knowledge creation during the scenario development. Graduates and practitioners are asked to review the summarized trends and drivers and state the rationale concerning priorities among trends. For example, they might be asked to assess the probability that the trend will occur and impact of the trend on the development of the field. Further, they are urged to describe other trends they deem important for the future development of the field and their influences. Once students have 
developed their scenarios, in another feedback loop, teachers, practitioners, and graduates provide feedback on the scenarios and suggest improvements.

\section{Technology-enabled learning environment}

The virtual, technology-enabled learning environment is created for students, teachers, graduates, and practitioners to collaborate in scenario development. Teachers are expected to provide guidance on setting up PLE\&N, specifically in setting up a Google+ community, popular social networking software, which has been chosen as a technology option for the model. Teachers upload learning materials related to the subject field, such as links to massive open online courses, YouTube videos, and websites, video lectures, industry news and articles, and academic reports. The learning related features in Google+ include students' posting, where students may submit posts with multimedia content and peer review, where students review other students' posts and provide constructive comments and feedbacks. Moreover, each student is asked to record a short video (up to 5 minutes duration) describing the developed scenario and submit to FlipGrid, a video sharing and discussion platform, for peer review and for teacher`s assessment.

\section{Steps of the model}

\section{Defining focus question and updating course activities}

Teachers define focus question for students and consider how far ahead in terms of years students should extend their scenario thinking. Furthermore, they make decisions on how to operationalize the model, i.e., they decide how a course in part of the semester should be revamped to cover techniques on scenario development. There are different ways to incorporate the students' scenario development activities: 1) Part of a project (with assessment); 2) Part of an assignment (with assessment); 3) In-class activity (with or without assessment). Scenario development activities can be conducted in multiple cycles during the semester. Teacher designs class activities and assignments for groups of students to learn and apply scenario development techniques.

\section{Students'scenario development}

To facilitate students' scenario development, a condensed version of the deductive matrix approach is used (Schwarz, 1991; Van der Heijden, 2011). As students consider the process of developing scenarios for subject development, they are encouraged to look at changes occurring in the broader socio-technical environment and to identify critical uncertainties. Once a scenario framework based on the four quadrants is designed, scenario logic can be developed into four fully developed scenarios with narratives - absorbing, convincing stories. Specifically, the proposed scenario development process includes the following stages: (1) choosing focus question, (2) identifying trends and driving forces, (3) identifying uncertainties, (4) generating scenario logics, (5) creating scenario narratives. Scenarios are documented in a textual form, in a structured manner to depict the scenario in a narrative form and highlighting critical uncertainties that form a base for the scenario. By adapting and building on the framework developed by Cheng et al. (2016), students describe scenarios to answer the following questions: What is the possible scenario you are thinking about?, When will the scenario happen?, Where will the scenario happen?, Who will get involved in the scenario?, Why will the scenario happen?, How will the scenario happen? 
Assessment and updating the curriculum

The last phase of the implementation phase addresses the cyclic and iterative nature of the proposed approach. Once the scenario development is completed and students' views elicited in a form of scenario narratives, they are evaluated according to a set of criteria that is defined in the assessment sheet. Namely, assessment team comprising teachers and tentatively practitioners and graduates assess the scenarios based on the following criteria (van der Merwe, 2008; Amer et al., 2013): relevancy, i.e. scenarios have to be anchored in the current concerns and, at the same time, take the thinking beyond the current assumptions; plausibility, i.e. based on realistic assumptions; innovativeness, i.e. provide a story that is in some way surprising or new; consistency, i.e. the combination of logics in a scenario has to ensure that there is no built-in internal inconsistency and contradiction. Teachers, according to their assessment, update the curriculum before the next delivery of the course.

\section{Discussion}

The proposed approach is based on the premise that issues of opening curriculum and the contributing role of students are critical. Scenario development is used as an artifact to support collaborative creation of knowledge among students, teachers, graduates, and practitioners. In this way, the proposed approach signifies a shift in perspective on universities from places where knowledge learned outside the classroom is reported to students to one where students themselves become researchers, co-creators of knowledge, and co-creators of a curriculum. Namely, in traditional view learning is seen as an external, objective process where "knowledge has to be transmitted and received as an information, theories and research findings," and which learners after the reception use for their purposes (Zuber-Skerritt, 2002). In contrast to this view, in our approach, it is recognized that there is a possibility for learners to create knowledge by themselves, rather than just take it in passively. Through this approach, students are reflecting on the role of various driving forces and use different analysis techniques to understand their impact on the subject field based on the specific focus question. Embedding scenario development into a sustained social learning process allows participants to learn through experience and application. Participating in the practice of scenario development is a way to gain knowledge in action (Gherardi et al., 1998). Engaging students in scenario development aims at empowering them, stimulating shared sensemaking, giving them a sense of ownership of the results, giving them the thrill of discovery and invention, and stimulating subsequent action (McBride et al., 2017). The use of scenario development in iterative, reflexive cycle represents the use of scenarios as a tool for ongoing students` learning and adaptive curriculum renewal.

Knowing how to assess the current trends, their impact and rightly forecast the ongoing development of a field are no doubt of immense importance to entrepreneurs, knowledge workers, and businesses. We believe that educating professionals to address these issues is of a critical importance. The proposed approach represents an innovation in delivering educational services with its focus on democratizing learning boundaries, inspiring individual and collective wisdom by collaboration, and processes for a continuous alignment of curriculum with emerging subject knowledge. Furthermore, this approach prepares students to "learn to learn", enhances their confidence, and cultivates their 
appreciation of the external environment prior to their graduation. Altogether, this approach is very promising in preparing a learner for the uncertain future.

\section{Conclusion}

This paper discusses the co-creation of curriculum among teacher, students and graduates, based on an opening curriculum approach to incorporate students inputs by using scenario development and personal learning \& network tools. As depicted by the proposed model, students do not learn passively (e.g. in taught classes) as in traditional transfer model but actively construct knowledge relevant for the subject field by drawing on trends and drivers in the broader socio-technical environment. Students work in a technology-enabled learning space and use well-designed scenario development steps to create a relevant knowledge base for how the subject field might evolve. They are supported by teachers, practitioners, and graduates who are experts in these areas. The model provides benefit to students as it equips them with the ability to sense the environment, reflect, and generate informed opinions of the trends and developments in the subject field. Teachers, by reflecting on and assessing scenarios, are better informed about the trends and developments in a subject field, which allows them to update the curriculum regularly and appropriately.

The proposed approach supports individual and group-based lifelong learning and is compatible with the contemporary requirements of the higher education to equip students with an ability to navigate through and adapt to constant change and work in an increasingly digitalized and networked economy. The approach might be considered by practitioners as a potential way forward to achieve continuous curriculum renewal by opening curriculum to student input. Furthering our discussion here, trialing and evaluation of the proposed method in a graduate and postgraduate courses in a university will be our next step.

\section{Acknowledgement}

The work described in this paper was fully supported by Teaching Development Grant (TDG) 2016-19 and administered by Learning and Teaching Committee of the Hong Kong Special Administrative Region, China (Project No. LTG16-19/LS/ISE1)

\section{References}

Albert, M., \& Beatty, B. J. (2014). Flipping the classroom applications to curriculum redesign for an introduction to management course: Impact on grades. Journal of Education for Business, Vol. 89, No. 8, pp.419-424.

Amer, M., Daim, T. U., \& Jetter, A. (2013). A review of scenario planning. Futures, 46, 23-40. Chapman, S., \& Randall, L. (2012). A new process model for curriculum development in business education. The Business Review, Cambridge, Vol. 20, No. 1, pp. 9-16.

Cheng, M. N., Wong, J. W. K., Cheung, C. F., \& Leung, K. H. (2016). A scenario-based roadmapping method for strategic planning and forecasting: A case study in a testing, inspection and certification company. Technological Forecasting and Social Change, 111, 44-62.

Chermack, T. J., Lynham, S. A., \& Ruona, W. E. (2001). A review of scenario planning literature. Futures Research Quarterly, Vol. 17, No. 2, pp. 7-32. 
Dabbagh, N., \& Kitsantas, A. (2012). Personal Learning Environments, social media, and selfregulated learning: A natural formula for connecting formal and informal learning. The Internet and higher education, Vol. 15, No. 1, pp. 3-8.

Duncan, N. E., \& Wack, P. (1994). Scenarios designed to improve decision making. Planning Review, Vol. 22, No. 4, pp. 18-46.

García Peñalvo, F. J., Conde García, M. Á., Alier Forment, M., \& Casany Guerrero, M. J. (2011). Opening learning management systems to personal learning environments. Journal of universal computer science: J. UCS, Vol. 17, No. 9, pp. 1222-1240.

Gherardi, S., Nicolini, D., \& Odella, F. (1998). Toward a social understanding of how people learn in organizations: The notion of situated curriculum. Management Learning, Vol. 29, No. 3, pp. 273-297.

Kolb, D. A. (1984). Experiental learning. Englewood Cliffs.

Leone, S. (2013). Characterization of a personal learning environment as a lifelong learning tool. Springer Science \& Business Media.

Masini, E. B., \& Vasquez, J. M. (2000). Scenarios as seen from a human and social perspective. Technological Forecasting and Social Change, Vol. 65, No. 1, pp. 49-66.

McBride, M., Lambert, K., Huff, E., Theoharides, K., Field, P., \& Thompson, J. (2017). Increasing the effectiveness of participatory scenario development through codesign. Ecology and Society, Vol. 22, No. 3, Article 16.

Ringland, G., \& Schwartz, P. P. (1998). Scenario planning: managing for the future. John Wiley \& Sons.

Ogilvy, J., \& Schwartz, P. (2004). Plotting your scenarios. Global Business Network.

O'Keefe, R. (2013). Applying Principles of Innovation to Curriculum Revision. International Journal of Innovation Science, Vol. 5, No. 3, pp.173-178.

Oliver, B. (2013). Graduate attributes as a focus for institution-wide curriculum renewal: innovations and challenges. Higher Education Research \& Development, Vol. 32, No. 3, pp. 450-463.

Schoemaker, P. J. H. (2015). Uncertainty, Navigating of: From Scenarios to Flexible Options. In Wiley Encyclopedia of Management. John Wiley \& Sons, Ltd.

Schon, D. A. (1984). The reflective practitioner: How professionals think in action (Vol. 5126). Basic books.

Sitlington, H., \& Coetzer, A. (2015). Using the Delphi technique to support curriculum development. Education + Training, Vol. 57, No. 3, pp. 306-321.

Tsang, H. W. C., \& Tsui, E. (2017). Conceptual design and empirical study of a personal learning environment and network (PLE\&N) to support peer-based social and lifelong learning. VINE Journal of Information and Knowledge Management Systems, Vol. 47, No. 2, pp. 228-249.

Tsui, M. L., Tsui, E., \& See-To, E. W. (2013). Adoption of a personal learning environment \& network (PLE\&N) to support peer-based lifelong learning. International Academic Forum (IAFOR).

Van der Heijden, K. (2011). Scenarios: the art of strategic conversation. John Wiley \& Sons.

Van der Heijden, K., Bradfield, R., Burt, G., Cairns, G., \& Wright, G. (2002). The sixth sense: Accelerating organizational learning with scenarios. John Wiley \& Sons.

Van der Merwe, L. (2008). Scenario-Based Strategy in Practice: A Framework. Advances in Developing Human Resources, Vol. 10, No. 2, pp. 216-239. 
Van Notten, P. (2006). Scenario development: a typology of approaches. Think Scenario, Rethink Education.-Paris: OECD Publishing, 69-84.

Vygotsky, L. S. (1980). Mind in society: The development of higher psychological processes. Harvard university press.

Zuber-Skerritt, O. (2002). The concept of action learning. The Learning Organization, Vol. 9, No. 3, pp. 114-124. 